\title{
Cuando los hijos se quedan en El Salvador: Familias transnacionales y reunificación familiar de inmigrantes salvadoreños en Washington, D.C. ${ }^{1}$
}

\author{
RAÚl SÁNCHEZ MOLINA \\ Dpto. Antropología Social y Cultural
}

UNED. Madrid

\section{RESUMEN}

Los actuales movimientos migratorios están propiciando el desarrollo de patrones socioculturales transnacionales que, en el ámbito de las unidades domésticas, permiten configuraciones de familias transnacionales. A partir de los datos obtenidos en una investigación etnográfica transnacional, este artículo describe y analiza las estrategias de inmigrantes en la reestructuración de sus familias. La lógica de la unidad familiar, por un lado, y los modos de incorporación de los salvadoreños al área metropolitana de Washington, D.C., por otro, explican las estrategias utilizadas por los inmigrantes en las reestructuración de sus unidades domésticas. De tal manera que hasta que los miembros de la familia puedan estar juntos de nuevo, tanto los patrones culturales premigratorios, como los adquiridos en las sociedades de asentamiento influyen en las configuraciones de las familias transnacionales.

Palabras claves: Inmigrantes salvadoreños, Políticas migratorias, Washington, D.C., Trasnacionalismo, Familia.

\section{SUMMARY}

Current migratory flows develope new social-cultural patterns such as transnational families. Using ethnographic data collected in Washington, D.C. and El Salvador, this article describes and analyzes the different strategies develop by Salvadoran immigrants

${ }^{1}$ Este artículo se basa en los datos obtenidos en la investigación etnográfica "Inmigración y redes familiares transnacionales. Una etnografía sobre familias salvadoreñas en el área metropolitana de Washington, D.C.». El trabajo de campo ha sido realizado con inmigrantes salvadoreños asentados en Washington D.C. y con sus familias en distintas localidades de El Salvador (San Miguel, La Unión y Soyapango). Este proyecto, que comenzó en 1999, debe su continuidad al apoyo prestado por el Departamento de Antropología de The Catholic University of America (Washington, D.C.) y el Departamento de Psicología Social y Antropología de la Universidad de Salamanca.

RDTP, LIX, 2 (2004): 257-276 
living in the Washington, D.C. metropolitan area to re-shape their domestic units. The immigrant modes of incorporation into the US societies and the logic of family unity affect these configurations to such an extent that until all the family members can be together again, the pre-migratory cultural patterns and those acquired in the host society affect in the transnational family configurations.

Key words: Salvadoran immigrants, Migratory policies, Washington, D.C., Transnationalism, Family.

La construcción de comunidades transnacionales como consecuencia de los actuales flujos migratorios sitúa a la familia como uno de los objetos de mayor interés de las actuales investigaciones en ciencias sociales. Distintos estudios han destacado el desarrollo de familias transnacionales $\mathrm{o}$ unidades domésticas multilocales — cuyos miembros están viviendo en al menos dos estado-nación- como uno de los fenómenos socio-culturales característicos de la globalización (Basch et al. 1994; Hondagneu-Sotelo y Avila 1997; Salazar 2001). Con estas configuraciones los emigrantes, que buscan alternativas para maximizar sus recursos en la economía global, se esfuerzan en mantener sus unidades domésticas premigratorias frente a las duras condiciones estructurales que les imponen las actuales políticas migratorias de los países receptores (Chavez 1991; Kibria 1993). En el caso de la migración salvadoreña a Estados Unidos, las investigaciones realizadas en la última década han destacado la importancia que la familia adquiere en el desarrollo de las redes migratorias y del transnacionalismo (Montes 1990; Repak 1995; Mahler 1995; Menjívar 2000; Landolt et al. 1999). Sin embargo, poca atención se ha prestado al estudio en particular de las configuraciones de familias transnacionales ${ }^{2}$. Lucy Cohen destaca la necesidad de investigaciones en esta dirección al resaltar la importancia del impacto que las reconfiguraciones de las unidades domésticas y de parentesco durante el proceso migratorio tienen, tanto para los padres, como para sus hijos, una vez que la reunificación familiar se lleva a cabo en la sociedad de acogida (Cohen 1999). Esta investigación pretende un acerca-

\footnotetext{
2 Segundo Montes (1990) destacaba la influencia que la emigración a Estados Unidos ejercía en la desestructuración de las familias. Terry Repak (1995) y Sarah Mahler (1995) inciden en la importancia de las estructuras político-económicas en las dinámicas reticulares de la migración salvadoreña en Estados Unidos y, en consecuencia, en las familias. Cecilia Menjivar (2000) enfoca su análisis en las dinámicas y contingencias familiares al subrayar la importancia que las condiciones estructurales en las sociedades de asentamiento tienen para los salvadoreños en San Francisco. El equipo de Landolt, por otra parte, centra su estudio en la influencia que las actividades familiares de los inmigrantes ejercen en el desarrollo del transnacionalismo (Landolt et al. 1999).
} 
miento al tema, centrando su interés en familias salvadoreñas cuyos progenitores han emigrado al área metropolitana de Washington, D.C. dejando sus hijos en El Salvador ${ }^{3}$.

Los modos de incorporación de los salvadoreños al área metropolitana de la capital norteamericana -es decir, las políticas migratorias, las oportunidades en el mercado de trabajo y las características étnicas que los inmigrantes encuentran en los contextos de asentamiento (Portes y Manning 1986: 49-51) - influyen en la conformación y mantenimiento de familias transnacionales. En este estudio se observa que los inmigrantes salvadoreños reestructuran sus unidades domésticas en función de los modos de incorporación, así como de los vínculos que estos mantienen con la unidad doméstica premigratoria, el género, las etapas de asentamiento y los ciclos vitales de los hijos que se quedan en El Salvador (Kibria 1993; Forner 1997). Los patrones múltiples y dinámicos en la reconstrucción transnacional de las familias dejan de manifiesto la flexibilidad y capacidad de adaptación de éstas a los cambios que imponen las actuales condiciones macroestructurales (Grasmuck y Pessar 1991; Salazar 2001; Fábrega y Tomé 2001). Los datos etnográficos obtenidos resaltan que la lógica de la unidad familiar explica las distintas configuraciones familiares que los salvadoreños realizan durante el proceso migratorio. Hasta el punto de que, aunque la unidad de los miembros que componen la familia puede lograrse con el retorno de los progenitores, la reunificación en la sociedad de acogida se convierte en la alternativa más aceptable, a pesar de los obstáculos impuestos por las actuales políticas migratorias a los inmigrantes indocumentados o con permisos de trabajo temporal ${ }^{4}$. En estos supuestos, la legislación favorece la separación de la unidad doméstica durante largos periodos temporales (Hondagneu-Sotelo 1994; Forner 1997; Cohen 1999). Mientras tanto, todos los miembros de la familia se ven envueltos en la paradoja de mantener la unidad en espacios dispersos, ideando estrategias transfronterizas que les permitan reestructurar sus familias a la espera de que la reunificación pueda efectuarse. Una vez que se reunifican, las familias sufren un nuevo proceso de reestructura-

\footnotetext{
${ }^{3}$ La definición y tipología de familia transnacional es amplia, dependiendo de las estructuras familiares y de los miembros que viven en otro país, abarcando configuraciones familiares monoparentales, nucleares o extensas en las cuales los que emigran pueden ser, además de los padres, hijos, hermanos, cuñados, tíos, abuelos, etc. (Chavez 1991; Salazar 2001).

${ }^{4}$ Aunque la reunificación familiar es uno de los principios básicos de la política migratoria estadounidense desde la aplicación de la Ley de Inmigración y Nacionalidad de 1965 (Immigration y Nationality Act), ésta únicamente se contempla en los supuestos de los ciudadanos estadounidenses o residentes permanentes.
} 
ción que implica un alto coste emocional y adaptativo como consecuencia de la separación previa (Cohen 1999: 383). Tanto los hijos como los padres necesitan construir nuevos espacios de referencias culturales de identidad y vinculación.

\section{WASHINGTON, D.C. LUGAR DE INCORPORACIÓN}

En las últimas décadas, el área metropolitana de Washington, D.C. se ha convertido en una de las regiones de mayor recepción de inmigrantes en Estados Unidos y los salvadoreños en su grupo más representativo ${ }^{5}$. Tanto factores políticos y económicos, acentuados durante la guerra civil en El Salvador (1981-1992), como el desarrollo de redes sociales explican el asentamiento de millares de salvadoreños en la región y su continuo crecimiento hasta la actualidad (Repak 1995). Esta trayectoria podría dividirse en tres periodos, marcados por condiciones estructurales y modos de incorporación cambiantes. El primero abarca desde finales de la década de los cincuenta hasta finales de los setenta del siglo $\mathrm{xx}$, durante el cual la presencia de salvadoreños en la ciudad no es numerosa (Repak 1995). El proceso de internacionalización de la capital estadounidense después de la Segunda Guerra Mundial conlleva el establecimiento de organizaciones internacionales y nacionales, públicas y privadas que demandan mano de obra en el sector del servicio ${ }^{6}$. A este mercado laboral comienzan respondiendo, entre otros grupos latinoamericanos, mujeres salvadoreñas; propiciando el desarrollo de incipientes redes migratorias que facilitan la incorporación discreta de nuevos inmigrantes ${ }^{7}$. Durante este periodo, las

\footnotetext{
${ }^{5}$ Los últimos datos del Censo 2000 contabilizan una población censada de cinco millones de personas, situando este área metropolitana como la séptima con mayor número de inmigrantes y de mayor crecimiento del país. Desde la década de 1980, coincidiendo con la masiva llegada de salvadoreños, la región ha crecido en 1.500 .000 de personas (42\%). Este alto crecimiento se debe fundamentalmente a la población inmigrante que se ha triplicado de 256.535 en 1980 a 832.016 en el 2000. Según estos mismo datos, la población salvadoreña representa el mayor grupo de inmigrantes del área $(12,6 \%)$ seguida de coreanos $(5,5 \%)$, indios $(5,5 \%)$, vietnamitas $(4,5 \%)$ y mexicanos (4\%) (US Census Bureau 2000, citado por Singer 2003: 8).

${ }^{6}$ Después de la II Guerra Mundial, se establecen en la capital las embajadas de países latinoamericanos y organizaciones multilaterales como la Organización de Estados Americanos (1948), el Banco Mundial (1950), o el Banco Interamericano de Desarrollo (1959). Con estas organizaciones se establecen en la ciudad otras corporaciones públicas y privadas especializadas en política exterior, seguridad y desarrollo internacional (Repak 1995; Cadaval 1998).

${ }^{7}$ Hasta la década de 1970, el setenta por ciento de la población latinoamericana en la ciudad estaba constituida por mujeres; fundamentalmente porque la ciudad y su
} 
políticas migratorias norteamericanas no son tan restrictivas y los inmigrantes salvadoreños no parecen encontrar grandes dificultades para obtener los permisos necesarios para asentarse con sus familias en la región.

El segundo periodo coincide con la guerra civil en El Salvador (19811992), durante el cual, y de manera vertiginosa, llegan las oleadas más importantes de salvadoreños huyendo de la violencia y la pobreza (Repak 1995; Mahler 1995; Menjívar 2000). Durante esta década, el área metropolitana experimenta un desarrollo económico importante con el establecimiento de industrias de alta tecnología y comunicaciones. El crecimiento de estas industrias propicia el auge de un mercado laboral poco remunerado en el sector servicios (Sassen 1991; Hamilton y Chinchilla 1991). Durante este periodo, la economía de la región demanda una mano de obra no cualificada en restaurantes, hoteles y oficinas, y segmentada por género en el servicio doméstico y la construcción (Repak 1995). Así pues, la guerra civil en El Salvador y el desarrollo económico del área metropolitana de Washington, D.C. favorecen la incoporación masiva de la inmigración masculina salvadoreña. Sin embargo, y a diferencia del periodo anterior, las políticas migratorias se vuelven más estrictas y, en el caso concreto de los salvadoreños, discriminatorias. La mayoría de los que llegan durante este periodo vienen con la esperanza de conseguir el estatuto político de refugiado; reconocimiento que únicamente logra obtener una minoría ${ }^{8}$. Esta situación, desfavorable para la mayoría de los que se incorporan durante esta época, provoca que sean considerados inmigrantes indocumentados, lo que les incapacita para trabajar legalmente (Menjivar 1999). Por otra parte, el gobierno norteamericano intenta frenar la entrada de indocumentados en el país, promulgando en 1986 la Ley de Reforma y Control de la Inmigración (IRCA, Immigration Reform and Control $A c t$ ). Con esta reforma legislativa, se penaliza a los empresarios que contraten inmigrantes indocumentados ${ }^{9}$. La nueva legislación ofrece, asimismo, un programa de amnistía general que permite la regularización de

área metropolitana no demandaba un mercado laboral que pudiera atraer a la población masculina (Repak 1995: 1-2).

${ }^{8}$ A penas un tres por ciento de los salvadoreños que se asentaron durante este periodo obtuvo el estatuto de refugiado; precisamente en un periodo en el cual El Salvador era considerado uno de los países con mayor índice de violencia (Gybney y Stohl 1988: 153).

${ }^{9}$ Esta reforma legislativa no consigue, sin embargo, detener la inmigración clandestina ni evitar que muchos empresarios prefieran contratar mano de obra más barata. Los salvadoreños llegaron a representar el segundo grupo con mayor número de indocumentados en el país, únicamente superado por los mexicanos (Hamilton y Chinchilla 1991: 77). 
aquellos salvadoreños que llegaron a Estados Unidos en los prolegómenos del conflicto bélico (antes de 1982).

El tercer periodo se inicia después de la firma de los acuerdos de paz (1992) y llega hasta la actualidad; está marcado por la crisis socioeconómica de la postguerra y las sucesivas catástrofes naturales que han sacudido El Salvador en los últimos años (el huracán Mitch y los terremotos de 2001). Durante esta época, tanto las políticas migratorias, cada vez más restrictivas, como la crisis económica de los noventa en Estados Unidos hacen que los modos de incorporación sean cada vez más difíciles para los salvadoreños. Gran parte de los inmigrantes que se incorporan durante este periodo se acogen al Estatuto de Protección Temporal (Temporary Protected Status) concedido por el Fiscal General, en primer lugar, como consecuencia de la discriminación que sufren los salvadoreños durante la guerra civil y, posteriormente, como consecuencia del Huracán Mitch y los terremotos del $2001{ }^{10}$. Este estatuto se ha ido extendiendo hasta la actualidad, permitiendo trabajar, asimismo, a los salvadoreños que llegaron antes del 2001. Esta situación migratoria, sin embargo, no permite a los hijos de los inmigrantes reunirse con sus padres en Estados Unidos, imposibilitando, en cualquiera de los casos, el contacto directo de los miembros de la familia en ambos países. En la actualidad, los salvadoreños representan el grupo de inmigrantes más importante del área metropolitana, estando altamente concentrados en la capital y en el condado de Fairfax, Arlington y Alexandria (Virginia), y los condados de Prince William y Montgomery (Maryland) ${ }^{11}$.

\section{MODOS DE INCORPORACIÓN Y SEPARACIÓN FAMILIAR}

El negocio más bueno que a mí me había funcionado, y en el que hice mucho dinero, era trabajar el tamal de carne y vender detalladamente a la gente porque tenía un puesto en el mercado donde vendía café, leche, chocolate, pupusas, plátano frito, frijolito [...] Ya en quiebra.con mi negocio, yo luché mucho, como cosa de unos seis años: "Si pongo otro, tal vez me funciona" [...] Y entonces dije yo: “No más negocio!" Tenía tanto miedo por haber quebrado con el primero...

${ }^{10}$ La Ley de Inmigración de 1990 (Immigration Act) introduce una autorización para que el Fiscal General pueda conceder el Estatus de Protección Temporal (Temporary Protected Status) a los extranjeros de países en guerra civil, desastres naturales y otras condiciones que impidan que los inmigrantes puedan regresar a su país. Se crea un programa especial para los salvadoreños desde 1992 que se ha ido extendiendo hasta la actualidad.

${ }^{11}$ Arlington y Alexandria no son condados administrativos; sólo Fairfax. Y, tanto el condado de Prince William, como Montgomery pertenecen a Maryland. 
¡Tenía demasiado! Y yo por eso no quería poner otro, que me decía yo: "Me fregaron en este negocio que yo tenía, de seguro que si pongo otro va a ser igual; no va a funcionar y, tal vez, me voy a enjaranar" [...] Cuando ya me sentí por completo derrotada con el negocio, empecé a luchar con mis hijas; a tratar de convencerlas: "Hijas, si yo me voy es por el bien de ustedes. Ustedes saben a la situación a la que hemos llegado. Si necesitan una ropa, yo no se las puedo comprar; si están deseando un bocado de comida buena, yo no se las puedo dar. ¡No más si alcanzo a darles dos tiempos de comida!" Mal alimentadas, sin vitaminas, sin nada... Uno vive así en nuestro país. Ya con pocas fuerzas para trabajar porque muy mal alimentadas. Así que trataba de convencerlas hasta que un día les dije: "Hijas, hoy ya tomé una decisión determinada; yo ya no voy a retroceder por nada; llore quien llore; me pase lo que me pase. Yo ya estoy decidida: yo me voy a ir y tengo toda la oportunidad de hacerlo" [...] A la primera que se lo dije fue a mi hija la mayor que entonces vivía aparte. Y ella me dijo: "Mamá por mi parte váyase, yo no la detengo. Es mi madre, le tengo gran aprecio, pero yo he visto desde cuándo viene luchando [...] Usted es una buena madre y entonces yo le digo: mamá, váyase".

Maria $R$

María R. emigra a Washington durante el tercer periodo, pero no sin antes haber contemplado las distintas alternativas para solucionar la grave situación económica que sufría su familia. La crisis económica de la postguerra propicia que esta mujer separada y con cinco hijos decida emigrar, siguiendo los pasos de sus padres, hermanos y hermanas que comenzaron el proceso migratorio durante la guerra civil ${ }^{12}$. Todos los miembros de la familia se asientan en el área sin documentos, con la salvedad de su madre y un hermano menor que logran acogerse a la reunificación familiar cuando su padre obtiene la residencia permanente como consecuencia de la amnistía de 1986 (IRCA).

La decisión de María R. no es el resultado de una resolución individual, sino que, por el contrario, se produce en el ámbito de la familia nuclear y extensa. Antes de tomar la decisión definitiva, y sabiendo que contaba con la ayuda de sus familiares asentados en Estados Unidos, que le ofrecen el apoyo financiero necesario para viajar y establecerse en la región, María R. negocia su partida con todos sus hijos. La decisión no fue fácil ya que este modo de incorporación significa la separación de los hijos por un periodo de tiempo imprevisible. Mientras tanto, María R. tiene que dejar resuelta una nueva estructuración de la unidad familiar, sobre todo, al tener que dejar en El Salvador a dos hijos menores de doce

${ }^{12}$ Distintos estudios destacan que cerca de una tercera parte de la población fue desplazada por la guerra civil (1981-1992) y factores relacionados con la situación política y económica que sufría el país (Zolberg et al. 1989; Rodríguez 1987; Hamilton y Chinchilla 1991). 
años; a quienes deja al cuidado de sus hijas mayores, solteras y dependientes de ella. Frente a los patrones clásicos migratorios controlados por los estados, los salvadoreños han desarrollado dinámicas migratorias reticulares promovidas en la mayoría de los casos por las familias (Portes 2000; Castles 2000). El desarrollo de estas redes informales permite a los nuevos inmigrantes superar los duros obstáculos que imponen las políticas migratorias (Massey et al. 1987) y las condiciones estructurales cambiantes de los lugares de asentamiento (Menjivar 2000). En ausencia de la ayuda gubernamental, los inmigrantes dependen de la ayuda de estas redes para iniciar la emigración, adaptarse a los contextos de asentamiento y mantener los compromisos familiares ${ }^{13}$. Ante la imposibilidad de emigrar con toda la familia, los salvadoreños han seguido la estrategia de la cadena migratoria (Grasmuck y Pessar 1991), emigrando primero sólo uno de los esposos ayudado por sus familiares más cercanos, normalmente consanguíneos. Una vez que estos se establecen, ayudan a salir al esposo o la esposa y posteriormente, solamente cuando las condiciones en el lugar de asentamiento son óptimas, se plantean la reunificación con los hijos; sobre todo en aquellos casos en que éstos no poseen la edad mínima requerida para trabajar en Estados Unidos.

La primera consecuencia de este modo de incorporación es, por lo tanto, la separación de los miembros que componen la unidad doméstica; separación que resulta más traumática y compleja cuando, en el caso de las familias nucleares o monoparentales, quien emigra es uno o ambos progenitores (Chavez 1991: 118). De ahí que la decisión de emigrar requiera de un proceso de negociación familiar a menudo largo, calculado y difícil, en contextos de incertidumbres y especulaciones sobre las personas que les asisten en el proceso migratorio (Hondagneu-Sotelo 1994: 18). Con todo, tanto los riesgos como las consecuencias que impone este modo de incorporación afectan a todos los miembros de la familia (nuclear y extensa). En primer lugar, en cuanto que los hijos tienen que reagruparse en nuevas unidades domésticas dirigidas por tutores que se comprometan a cumplir funciones de padres sustitutorios (Cohen 1999: 385). $\mathrm{Y}$ en segundo lugar, en cuanto que los familiares que reciben a los nuevos inmigrantes, además de invertir en muchas ocasiones el dinero y la asistencia necesaria para que la migración pueda darse, deben realizar

\footnotetext{
${ }^{13}$ En su estudio sobre la inmigración salvadoreña en San Francisco, Cecilia Menjívar destaca que estas expectativas pueden verse, no obstante, frustradas a lo largo del proceso migratorio destacando cómo las estructuras del lugar de asentamiento influyen en la ayuda que los inmigrantes reciben de sus allegados. De ahí que se deba tener en cuenta que no siempre los inmigrantes reciben la ayuda que esperan y necesitan de sus redes más inmediatas (Menjívar 2000: 116).
} 
nuevos reajustes en sus hogares ${ }^{14}$. De ahí que durante las primeras etapas del proceso migratorio, tanto los que emigran como sus hijos, dependan de la ayuda que sus redes más inmediatas pueden prestarles; ayuda que, en cualquiera de los casos, está condicionada por las estructuras de oportunidades que los inmigrantes encuentran en las sociedades de asentamiento (Menjivar 2000). Como destaca Lucy Cohen, los mayores cambios que produce la migración se dan en las unidades domésticas en cuanto que, por un lado, las familias se separan para facilitar la migración y, por otro, la adaptación a las condiciones sociales y culturales en las sociedades de acogida exige a los inmigrantes una rápida reconfiguración de aquéllas (Cohen 1999: 384).

\section{RE-ESTRUCTURACIONES FAMILIARES}

Llegué hace dos meses como mojada dejando dos hijos en El Salvador que tuve de dos acompañamientos. Mis hijos están en casa de mi madre en El Salvador y ella me los cuida.

Mirian A.

Cuando Mirian A. emigra a Washington deja a dos hijos menores en El Salvador al cuidado de su madre y sus hermanas. Los compatriotas que como ella salen dejando a sus esposos/esposas, hijos e incluso nietos en El Salvador, tienen que reorganizar previamente sus familias antes de aventurarse a un proceso migratorio que se inicia, como ya se ha señalado, lleno de incertidumbres sobre el viaje, las condiciones de asentamiento y el tiempo de separación de la familia. Las primeras configuraciones familiares que realizan dependen de quién sea el que emigra. Si es el padre, los hijos menores suelen quedarse con la madre en la residencia familiar previa a la migración. Y si es la madre o ambos cónyuges, los hijos menores suelen trasladarse a la residencia de la abuela o tías maternas en los casos en que no tengan hermanas mayores que puedan cuidar de ellos.

El caso de Mirian A. destaca la importancia que las estructuras matrilineales y matrilocales tienen en la incorporación de mujeres salvadoreñas con hijos a la migración transnacional (Cohen 1981; Repak 1995). Estas estructuras se han formado en El Salvador durante el siglo Xx como consecuencia de las migraciones regionales de carácter cíclico, protagoni-

${ }^{14}$ Que pueden ser familiares consanguíneos, políticos, vecinos o conocidos (Cohen 1981: 181). 
zadas, inicialmente, por los hombres, siguiendo la extensión de monocultivos para la exportación. Estos patrones migratorios inciden en la formación de "acompañamientos" o uniones libres —unidades doméstica en las que no se establecen vínculos legales entre cónyuges- entre las poblaciones campesinas y urbanas más pobres ${ }^{15}$. Aunque el matrimonio legal continuó siendo el ideal cultural en la formación de la familia, tanto la inestabilidad laboral —que obliga a muchos hombres a emigrar dejando mujeres e hijos - como la falta de propiedades hereditarias, contribuyen a que la presión social sobre el matrimonio disminuya. La guerra civil, y el consiguiente éxodo migratorio de hombres huyendo de la posibilidad de verse enrolados en el conflicto armado, favoreció el aumento de los "acompañamientos" o uniones libres, de familias monoparentales dirigidas por mujeres y la formación de familias nucleares sucesivas por parte de los hombres (Brewer 1983; Thomson 1986). Estos factores han propiciado que se fortalezcan las estructuras de familias extensas de carácter matrilocal que favorecen la emigración significativa de madres salvadoreñas a Estados Unidos y el desarrollo en la actualidad de familias transnacionales.

\section{DESESTRUCTURACIÓN Y REESTRUCTURACIÓN DE LA FAMILIA PREMIGRATORIA}

Problema de matrimonio no había, pero tantos años fuera de la casa... Hay cosas muy duras, que sólo el que las vive las comprende, porque la situación mía fue que ella se quedó allá. Ella se metió entonces con alguien y ese cuento no se perdona... Yo no aguanto eso.

Juan $V$.

Juan V. emigra sin documentos a Washington, D.C. a comienzos del segundo periodo, dejando en El Salvador a una esposa, en régimen de acompañamiento, y cinco hijos residiendo en el lugar de origen de ambos progenitores. Cuando después de varios años, Juan V. regresa a El Salvador, un primo directo le informa de que su esposa se había estado relacionando con otro hombre durante su ausencia. Juan V. decide entonces separarse de ella y regresar nuevamente a Estados Unidos. Una vez establecido en Washington, consigue la residencia permanente a través de la aministía de 1986 (IRCA), lo que le permite, asimismo, acogerse al derecho de reunificación familiar. Se plantea entonces iniciar el proceso

${ }^{15} \mathrm{El}$ desarrollo de estas configuraciones familiares se dio fundamentalmente entre la clase campesina que en un primer momento tenía que desplazarse a otras regiones del país o de los países del entorno para las cosechas del café, el algodón o la caña de azúcar (Menjivar 2000: 47). 
migratorio de los cinco hijos que había dejado en El Salvador y que, para entonces, ya tenían la edad requerida para trabajar en Estados Unidos. Los hijos de Juan V. se fueron instalando en Washington en residencias independientes a la de su padre, ya que éste había iniciado un segundo acompañamiento con una inmigrante salvadoreña con la que tiene otros dos hijos. El estatuto de residente, por otra parte, permite a Juan V. viajar asiduamente a El Salvador. En uno de estos viajes, que realiza sin la compañía de su segunda mujer, Juan $\mathrm{V}$. conoce a la que se convertiría en su tercera esposa y con la que decide contraer matrimonio civil y eclesiástico. Fruto de este tercer matrimonio tiene otros cuatro hijos que permanecen, por expreso deseo suyo, junto a su madre en El Salvador mientras él regresa a Estados Unidos. Durante un periodo Juan V. estuvo conviviendo y manteniendo la segunda familia establecida en Washington y la tercera en El Salvador con el conocimiento de ambas mujeres. Finalmente, y por presiones de la tercera esposa, Juan V. decidió abandonar el hogar donde convivía con la segunda familia, negociando sus responsabilidades paternas y con la intención de regresar definitivamente a $\mathrm{El}$ Salvador.

La migración puede producir rupturas familiares como consecuencia de la falta de cohabitación entre los esposos, el cambio en la división del trabajo o por el desarrollo de nuevos roles de género en la sociedad de asentamiento (Salazar 2001: 109). El caso de Juan V. ilustra algunos de estos factores en la desestructuración de las familias premigratorias y en el establecimientos de nuevas familias durante el proceso migratorio. En esta dirección apuntaba Segundo Montes al interpretar que la migración salvadoreña a Estados Unidos contribuía al desmantelamiento de los hogares y a la desestructuración de las familias cuando ésta la iniciaba uno de los progenitores (Montes 1990: 85). La incorporación clandestina obliga a los inmigrantes, en un primer momento, a permanecer largas temporadas separados de sus parejas e hijos. Durante este periodo, los inmigrantes se esfuerzan en regularizar su situación, al tiempo que buscan distintas alternativas de adaptación a las duras condiciones que les imponen las sociedades de asentamiento. Sin embargo, en estas respuestas encontramos significativas diferencias de género en las que se reflejan vínculos mayores y más constantes de las mujeres con los hogares premigratorios. Asimismo, se puede apreciar en algunos casos cierta tendencia en los hombres a establecer nuevas familias nucleares tanto en los lugares de asentamiento como de partida.

Como consecuencia del proceso migratorio, valores culturales tradicionales en torno a los roles de género dentro de la familia pueden, asimismo, reforzarse. El mayor protagonismo que las mujeres inmigrantes consi- 
guen en el lugar de asentamiento ha revitalizado en algunos casos tradiciones de carácter patriarcal como el control social sobre la mujer (Mahler 1999: 709). En este sentido, y como podemos advertir en la reacción de Juan V. después de escuchar los comentarios sobre las infidelidades de su primera esposa, la emigración favorece el control social sobre la conducta sexual de las mujeres de emigrantes que permanecen en El Salvador (Montes 1990; Lungo y Kandel 1999). Este control social explica la preferencia de algunos hombres por contraer matrimonio en El Salvador con la intención de que sus mujeres permanezcan allí al cuidado de sus hijos y posesiones. En estos casos, en los cuales los inmigrantes suelen disfrutar de la residencia permanente o la ciudadanía norteamericana, tanto la revitalización de valores tradicionales, como pequeñas inversiones económicas realizadas en el lugar de origen favorecen el desarrollo de familias transnacionales a la espera de que la reunificación familiar pueda efectuarse con el retorno parcial o definitivo del progenitor. Sin embargo, el establecimiento de nuevas familias nucleares no significa, al menos entre los casos registrados en esta investigación, que los hombres se desentiendan de los hijos tenidos en anteriores relaciones. En la mayoría de ellos, los progenitores animan a sus hijos, cuando alcanzan la edad para poder trabajar, a emigrar a Washington y establecerse en el área.

\section{DE LAS FAMILIAS TRANSNACIONALES A LA REUNIFICACIÓN FAMILIAR}

Hablo con mi mamá por teléfono tres veces al mes, y mi mamá me dice que estudie, que me cuide, me dice que le haga caso a las bichas y que no ande peleando con ellas [...] Cuando mi mamá nos manda pisto salimos, mis hermanos y yo, a comer pizza, a veces vamos al Pollo, y también, cuando vamos a cambiar el dinero a Unicentro, ahí veo qué compro [...] Prefiero que mi mamá esté más tiempo en Estados Unidos, porque así, cuando llegue aquí, va a poder comprar una casa, ahorrar, y si trae dinero, va a poder poner un buen negocio aunque también me gustaría ir para allá porque allá, aunque se trabaja mucho, mi mamá me dice que hay más cosas y se vive mejor.

Silvia $R$.

Silvia R. tiene catorce años y lleva cinco separada de su madre, viviendo en El Salvador con sus hermanas mayores. Ante la imposibilidad de su madre de viajar a El Salvador, y de Silvia R. de visitar a la madre en Washington, el contacto telefónico es el medio más inmediato que su madre tiene para seguir la situación y las necesidades de la familia. Como ya han destacado distintos estudios, los inmigrantes superan las barreras espaciales que les separan de sus familias gracias a los flujos de información y de dinero instantáneos que permiten los actuales avances tecnoló- 
gicos (Basch et al. 1994; Salazar 2001). Las tensiones que genera la dispersión espacial, las incertidumbres sobre el retorno o la permanencia y los compromisos familiares favorecen el desarrollo y el afianzamiento de relaciones transnacionales.

La primera relación transnacional que los inmigrantes establecen con sus lugares de origen se da a través de las remesas que envían para la subsistencia y la mejora de la calidad de vida de los miembros de la familia (Montes 1990; Landolt et al. 1999). Como señala Salazar Parreñas (2001: 124), en estas relaciones el consumo juega también un papel importante como mecanismo compensatorio por la separación familiar. Únicamente cuando estos compromisos inmediatos quedan garantizados, las remesas se destinan a pequeñas inversiones para la construcción o la compra de viviendas en el lugar de origen (Landolt et al. 1999; Mahler 1999). Estas inversiones en bienes inmobiliarios se convierten, asimismo, en iconos que visibilizan -además del orgullo de haber prosperado en la empresa migratoria - el valor de la unidad familiar, el cumplimiento del compromiso filial y el deseo de reunificación en el lugar de origen (Fletcher 1999: 5). De tal manera que la tensión entre el "aquí o allá" refuerza, como señala Espinosa (1998: 44), el retorno como un mito ambivalente que favorece el desarrollo y mantenimiento de las redes migratorias. Y en esta misma medida, impulsa la creación de relaciones transnacionales que, en el ámbito de la familia, se expresan en las distintas estrategias que los inmigrantes aplican en el ejercicio de sus responsabilidades filiales.

Como ya se ha destacado, en este ejercicio se observan diversos patrones que dependen de los vínculos de los progenitores con las unidades domésticas y en los que el género marca diferencias importantes. El compromiso de los hombres tiende a ser mayor cuando la vinculación con la unidad doméstica se mantiene durante el proceso migratorio, ya sea por acompañamiento o matrimonio. En estos casos, los padres mantienen constantes contactos con sus esposas y sus hijos en El Salvador para informarse de la situación del hogar y de las necesidades de los miembros de la familia. Sin embargo, cuando el vínculo se reduce a la paternidad, al margen de la unidad doméstica, las obligaciones se centran en el envío de dinero como apoyo a la subsistencia, contactos telefónicos menos asiduos y, en cualquiera de los casos, la intención de ayudarles a emigrar cuando llegan a la edad laboral y así lo desean. Como han resaltado distintos trabajos sobre la maternidad transnacional, el compromiso de las mujeres se manifiesta mayor en cualquiera de los casos. Muchas madres procedentes de países emisores como Vietnam (Kibria 1993), México (Hondagneu-Sotelo y Avila 1997) o Filipinas (Salazar 2001), que se incor- 
poran a la migración como respuesta a la demanda laboral de los países más industrializados, ejercen la maternidad transnacional como estrategia frente a las fuertes restricciones legales que estos países imponen a la reunificación con sus hijos. En estas mismas condiciones se encuentran las mujeres salvadoreñas que, además del esfuerzo que les exige el desarrollo de mecanismos que les permitan mantener la supervivencia y la unidad familiar, se encuentran sometidas al control social por el hecho de estar separadas de sus hijos. Desde un punto de vista socio-cultural - como en el caso también de las madres mexicanas- tanto en El Salvador como en Estados Unidos, el ejercicio de la maternidad se valora en relación con el contacto y cuidado directo de los hijos en el mismo ámbito residencial (Hondagneu-Sotelo y Avila 1997: 552). Este ideal lo mantienen las mujeres inmigrantes salvadoreñas durante el tiempo que dura la separación; de ahí que continuamente se estén planteando las alternativas que les permitan superar el hecho transnacional en el ejercicio de su maternidad. En las sociedades de acogida, tanto las madres como los padres salvadoreños se esfuerzan por buscar las condiciones que les faciliten la reunificación con sus hijos (Cohen 1999: 283). Las familias transnacionales son, por lo tanto, configuraciones transitorias que se intentan superar con el retorno de uno o ambos progenitores, con la emigración gradual de los hijos, siguiendo los modos de incorporación de sus progenitores, o con la reunificación familiar en la sociedad de asentamiento, una vez que se obtienen los permisos legales requeridos.

\section{EL RETORNO A El SALVADOR COMO ALTERNATIVA}

Es que los niños cuando hablo con ellos me dicen que quieren estar conmigo. De ahí es que yo me voy a ir por eso. Sólo quiero, le digo a él, venir a viajar un poquito porque mis hijos están creciendo y quiero estar con ellos. Me voy a ir para estar con ellos y si me saliera alguna visa, yo me vengo con ellos porque me gustaría traérmelos a todos.

Rosa C.

Rosa C. llega a Washington durante el tercero de los periodos que hemos acotado para reunirse con su esposo, dejando ocho hijos en El Salvador al cuidado de sus padres y en edades comprendidas entre dos y trece años. Después de dos años, el retorno a El Salvador fue la única alternativa que tanto ella como su esposo encontraron para solucionar las tensiones generadas por la separación de la familia. Sin embargo, este retorno no fue contemplado por ambos de manera definitiva, sino con la 
esperanza de que el marido pudiera regularizar su situación legal, de forma que permitiera la reunión con todos sus hijos en Washington. Las estrategias que este matrimonio desarrolló para mantener una familia transnacional fueron insuficientes para paliar las consecuencias emocionales ocasionadas por la separación; agravando la situación del matrimonio para adaptarse a las duras condiciones de la sociedad de acogida, lejos de sus hijos ${ }^{16}$. Esta incapacidad hace que algunos inmigrantes encuentren en el retorno temporal de uno o ambos cónyuges la única alternativa de superar las tensiones que ocasionan la dispersión espacial de la familia.

\title{
LA INCORPORACIÓN SIN DOCUMENTOS DE LOS HIJOS
}

\begin{abstract}
Me sentí entonces tan acorralada, que me puse a pensar otra vez que yo no podía continuar sola como estaba y que si una de mis hijas hubiera estado conmigo, todo hubiera sido diferente [...] Así como yo estoy con esta enfermedad yo me doy cuenta cómo me sintiera teniendo a mi hija acá. Me sentiría más acompañada. Tal vez no hubiera tenido necesidad de venirme para acá si la tuviera a ella. Estaríamos viviendo las dos en un apartamento, o tal vez en un cuarto. Yo siento que la necesito mucho. Aún hoy que he estado muy enferma; ahora con mi enfermedad yo siento que yo necesito mucho a una de ellas.
\end{abstract}

María $R$.

María R. estuvo durante una temporada convaleciente primero en un hospital y después en la casa de unos familiares en Washington. Durante este periodo de convalecencia María R. vivió una situación crítica al tener que depender de la ayuda de familiares y conocidos. Gracias a esta ayuda fue capaz de hacer frente durante unos meses no sólo a los gastos médicos y farmacéuticos, sino, además, al envío mensual del dinero para el mantenimiento de sus hijos en El Salvador. Con todo, esta dura circunstancia y la incertidumbre de perder su trabajo o que esta situación pudiera repetirse, hacen que María R. se plantee la necesidad de que su hija de 24 años emigre a Washington como apoyo personal y económico. La única alternativa que la hija tenía para reunirse con su madre era sin documentos; incluso en el supuesto de que María R. tuviera la residencia permanente, su hija no hubiera podido reunirse con ella de forma regular al ser mayor de edad. Después de varios intentos frustrados al llegar a la

${ }^{16}$ Según Leo Chavez, los miembros de las familias transnacionales experimentan un fuerte estrés emocional como resultado de la separación y los cambios que se producen en el hogar como consecuencia de la emigración de los progenitores (Chavez 1991: 119). 
frontera, la hija se establece en Washington, ayudando a su madre emocional y económicamente. Este tipo de alternativa sólo es posible cuando la familia cuenta con hijos mayores que permitan a los padres hacer frente a las duras condiciones del proceso migratorio y a los gastos que supone el mantenimiento de una familia transnacional.

\title{
LA REUNIFICACIÓN FAMILIAR EN WASHINGTON
}

\begin{abstract}
Pensé todas las maneras para mandarlos a traer: pensé que fueran a México y que mi hermano, que es ciudadano, fuera a México y los pasara; pero el viaje de los niños es muy arriesgado porque pueden morir en el camino por un accidente o te los pueden robar. En México hay muchas personas que pasan a Estado Unidos, y si usted lleva un niño por la frontera no tiene tantos problemas para pasar porque son menores de edad y tienen más beneficios. Otra persona más lista le puede robar al niño y pasar al país y después los dejan botados. Pero ahora estoy muy contenta porque lo que he logrado, y es lo que más me ha gustado, es que logré que ellos vinieran y que ellos tengan su residencia y que estén aprendiendo otro idioma y superándose. Hay muchos niños indocumentados que no pueden ir a la universidad. Eso no es justo porque un niño es un niño. Hay muchos niños que llevan diez años en este país y están indocumentados; por ejemplo, mi sobrino tiene que aplicar para su TPS ${ }^{17}$ aparte de sus padres.
\end{abstract}

Isabel $M$.

Isabel M. llegó a Washington a principios del segundo periodo dejando a dos hijos de tres y un año en El Salvador al cuidado de su madre. Después de once años de separación, Isabel M. pudo reunirse nuevamente con sus hijos al obtener la residencia permanente ${ }^{18}$. Durante este largo periodo, y ante las desoladoras perspectivas de reunificación familiar como consecuencia de las restricciones legales, algunos padres como Isabel M. llegan a plantearse la entrada clandestina de sus hijos menores de edad. Sin embargo, muy pocas familias parecen dispuestas a aceptar esta solución, debido a los riesgos que conlleva. Como señala Isabel M., los niños reciben un trato especial por parte de las autoridades fronterizas, mientras que los adultos pueden ser detenidos al cruzar la frontera. En los relatos de viajes recogidos en esta investigación, mis informantes señalan distintos episodios en los que los niños son utilizados por los viajeros para facilitar la entrada en el país de adultos. La mayoría de los padres no parecen dispuestos, por una parte, a que sus hijos corran riesgos en el

${ }^{17}$ Estatuto de Protección Temporal (Temporary Protected Status).

${ }^{18}$ Lucy Cohen señala que los periodos de separación de los hijos pueden durar, dependiendo de las circunstancias del proceso migratorio, más de quince años (Cohen 1999: 283). 
viaje, ni, por otra, a que vivan la situación de incertidumbre y clandestinidad que ellos han vivido (Chavez 1991). De ahí que la mayor parte de las familias prefieran esperar a conseguir los requisitos legales exigidos por las políticas migratorias antes de plantearse la reunificación con sus hijos menores. Isabel $\mathrm{M}$. decidió finalmente esperar a conseguir la residencia permanente para reunirse nuevamente con sus hijos en Washington. Con todo, esta reunificación familiar no puede considerarse completa ya que los hijos de Isabel M. tuvieron que separarse de su abuela materna que durante once años había ejercido las funciones de madre. El sistema legal estadounidense no tiene en cuenta el concepto de familia extensa, considerando la posibilidad de reunificación familiar con los padres de los inmigrantes únicamente en los casos en los que se obtiene la ciudadanía. Tampoco considera la posibilidad para otros miembros de la familia no consanguíneos que, como en el caso de algunas familias salvadoreñas, hayan podido ejercer un papel tan importante en la familia como padres sustitutorios ${ }^{19}$.

Una vez que la reunión familiar puede efectuarse en el lugar de asentamiento, surgen nuevos retos, como consecuencia de los largos periodos de separación y los cambios experimentados durante ella. Todos los miembros de la unidad doméstica, o al menos, los que pueden reencontrarse deberán a aprender a convivir juntos, renegociando roles familiares que difieren de los ejercidos en espacios dispersos. En los casos en que la reunificación se da en un mismo ámbito residencial, implica un proceso de adaptación que en ocasiones resulta difícil y complejo. Como destaca Lucy Cohen, la reunificación puede acarrear problemas y trastornos adaptativos en los hijos, que tienen que sufrir una reestructuración del hogar y una nueva separación emocional de sus tutores o padres sustitutorios con quienes han convivido, en muchos casos, desde su más tierna infancia. Los padres sustitutorios se han convertido durante estos largos periodos en sus verdaderas referencias paterno-filiales, al tiempo que sus padres biológicos se han convertido en unos auténticos extraños (Cohen 1999: 283). Por otra parte, frente a los roles tradicionales de los hombres y mayores en El Salvador, tanto las mujeres como los niños adquieren mayor protagonismo en las esferas públicas y familiares en Estados Unidos (Kibria 1993; Hondagneu-Sotelo 1994) . De ahí que las relaciones de género y generación impliquen importantes retos para la familia como respuesta a las estructuras y normas socio-culturales dominantes en la sociedad de asentamiento.

${ }^{19}$ El proceso migratorio de muchas familias salvadoreñas intensifica profundos vínculos de reciprocidad con miembros de la familia extensa que no sólo se definen por las relaciones consaguíneas, sino también por amistad (Rodríguez Herrera 1999: 238). 
En resumen, los datos etnográficos recogidos en esta investigación destacan que la migración salvadoreña en Washington, D.C., dependiendo de los modos de incorporación y de las condiciones estructurales que se dan en los lugares de asentamiento, favorece la configuración de familias transnacionales que permiten a los inmigrantes mantener la unidad de la familia en espacios dispersos. El sistema legal migratorio, a pesar del principio de unidad familiar favorece la separación de la familia y su reestructuración en forma de familias transnacionales. Con todo, el establecimiento definitivo de los miembros de la familia en el lugar de asentamiento parece inevitable en la mayoría de los casos, desvaneciéndose con el tiempo la idea inicial del retorno definitivo. En el caso de las familias contactadas en esta investigación muy pocos progenitores han regresado definitivamente a El Salvador optando, cuando las condiciones estructurales lo exigen y/o las leyes migratorias lo permiten, por la reunificación familiar en el lugar de asentamiento.

\section{BIBLIOGRAFÍA CITADA}

BASCH, LINDA et al. 1994. Nations Unbound:Transnationalized Projects and the Deterritorialized Nation-State. Nueva York: Gordon and Breach.

BREWER, TOYe HELENA. 1983. "Women in El Salvador", en Revolution in Central America: 400-407. Boulder, Colo.: Westview Press. Stanford Central America Action Network.

BuRIEL, R. y T. DE MENT. 1997. "Immigration and Sociocultural Change in Mexican, Chinese, and Vietnamese American Families", en Booth et al. (eds.), Immigration and the Family: Research and Policy on U.S. Immigrants: 165-200. Mahwah, N.J.: Lawrence Eribaum Associates.

CADAVAl, Olivia. 1998. Creating a Latino Identity in the Nation Capital. The Latino Festival. Nueva York y Londres: Garland Publishing, Inc.

CASTLES, STEPHEN. 2002. "Migration and Community Formation under Conditions of Globalization. International Migration Review 36, 4: 1143-1168.

CHAVEZ, LEO. 1991. Shadowed Lives. Undocumented Immigrants in American Society. San Diego: Harcourt Brace College Publishers.

- 1994. "The Power of the Imagined Community: The Settlement of Undocumented Mexicans and Central Americans in the United States". American Anthropologist 96, 1: $52-73$.

Cohen, LuCY. 1981. "Latinas Lead the Way", en Dolores Mortiner y Roy Bryce-Laporte (eds.), Female Immigrants to the United States: Caribbean, Latin American, and African Experiences: 179-202. Washington, D.C. : RIIES Occasional Papers No. 2. Research Institute on Immigration and Ethnic Studies. Smithonian Institution.

- 1999. "Maintaining and Reunifying Families: Two Case Studies of Shifting Legal Status", en David Haines y Karen Rosenblum (ed.), Illegal Immigration in America. A Reference Handbook: 383-395. Westport, Connecticut, London: Greenwood Press.

COHEN, LUCY y CARMEN FERNÁNDEZ. 1974. "Ethnic Identity and Psychocultural Adaptation of Spanish-Speaking Families". Child Welfare 53: 413-422. 
EsPINOSA, V. 1998. El dilema del retorno. Migración, género y pertenencia en un contexto transnacional. Zamora (Mich.): El Colegio de Michoacán.

FÁBregas, ANDRÉS y PEDRO TOMÉ. 2001. Entre parientes. Estudio de caso en México y España. Jalisco: Colegio de Jalisco.

FletCher, PERI. 1999. La Casa de Mis Sueños. Dreams of Home in a Transnational Mexican Community. Boulder, CO: Westview Press.

FORNER, NANCY. 1997. "The Immigrant Family: Cultural Legacies and Cultural Changes". International Migration Review 31, 4: 961-974

Grasmuck, SHERry y PATricia PESSAR. 1991. Between Two Islands. Dominican International Migration. Berkeley: University of California Press.

GYBNEY, MARK y MICHAEL STOHL. 1988. "Human Rights and U.S. refugee Policy", en Mark Gibney (ed.), Open borders? Closed societies?: The ethical and political issues: 151-183. Nueva York: Greenwood Press.

Hamilton, NORA y NORMa Chinchilla. 1991. "Central American Migration: A Framework for Analysis". Latin American Research Review 26, 1: 75-110.

HONDAGNEU-SOTELO, P. 1994. Gendered transitions: Mexican experience of immigration. Berkeley: University of California Press.

Hondagneu-Sotelo, P y E. Ávila. 1997. "I'm Here, but I'm There: The meanings of Latino Transnational Motherhood. Gender \& Society 11, 5: 548-571.

KIBRIA, NAZLI. 1993. Family tightrope: the changing lives of Vietnamese Americans. Princeton: Princeton University Press.

LANDOLT, PATRICIA et al. 1999. "From Hermano Lejano to Hermano Mayor: the dialectics of Salvadoran transnationalism". Ethnic and Racial Studies 22, 2: 290-315.

LUNGO, MARIO y SUSAN KANDEL. 1999. "Migración internacional y actitudes frente al trabajo en áreas rurales", en Mario Lungo y Susan Kandel (comps.), Transformando El Salvador. Migración internacional, sociedad y cultura: 97-124. San Salvador: Fundación Nacional para el Desarrollo.

MAHLER, SARAH. 1995. Salvadorans in Suburbia. Symbiosis and Conflict. Boston: Allyn and Bacon.

-. 1999. "Engendering Transnational Migration. A Case Study Of Salvadorans". American Behavioral Scientist 42, 4: 690-719.

MASSEY, Douglas et al. 1987. Return to Aztlan. The Social Process of International Migration from Western Mexico. Berkeley: University of California Press.

MENJÍVAR, CECILIA. 1999. "Salvadorans and Nicaraguans: Refugees Become Workers", en David Haines y Karen Rosenblum (eds.), Illegal Immigration in America. A Reference Handbook: 232-253. Westport, Connecticut, Londres: Greenwood Press.

-. 2000. Fragmented Ties. Salvadoran Immigrant Networks in America. Berkeley: University of California Press.

MONTES, SEGUNDO. 1990. El Salvador 1989. Las remesas que envian los salvadoreños de Estados Unidos. Consecuencias sociales y económicas. San Salvador: UCA Editores.

PORTES, AlEJANDRO. 2000. "Globalization from Below: The Rise of Transnational Communities", en Don Kalb et al. (eds), The ends of globalization: bringing society back in: 253-270. Lanham, MD: Rowman \& Littlefield Publishers.

PORTES, ALEJANDRO y ROBERT D. MANNUNG. 1986. "The Immigrant Enclave: Theory and Empirical Examples", en Susan Olzak y Joane Nagel (eds.), Competitive Ethnic Relations: 47-68. Orlando: Academic Press, Inc.

REPAK, TERRY. 1995. Waiting on Washington. Central American Workers in the Nation's Capital. Filadelfia: Temple University Press. 
Rodríguez Herrera, AmÉrica. 1999. "Migración, sociedad y cultura en Nueva Concepción. Una revisión desde la etnografía", en Mario Lungo y Susan Kandel (comps.), Transformando El Salvador. Migración internacional, sociedad y cultura: 223-270. San Salvador: Fundación Nacional para el Desarrollo.

RODRÍGUEZ, NÉSTOR. 1987. "Undocumented Central American in Houston: Diverse Populations". International Migration Review 21: 4-26.

SALAZAR PARREÑAS, RHACEL. 2001. Servants of globalization: women, migration and domestic work. Stanford: Stanford University Press.

SASSEN, SASKIA. 1991. The global city: New York, London, Tokyo. Princeton: Pricenton University Press.

SINGER, AUdREY. 2003. "At Home in the Nation's Capital: Immigrant Trends in Metropolitan Washington". Brooking Greater Washington Research Program. Washington, D.C.: The Brookings Institution.

THOMSON, MARILYN. 1986. Women of El Salvador. The Price of Freedom. Londres: Zed Press.

ZOLBERG, A. et al. 1989. Escape from violence: conflict and the refugee crisis in the developing world. Nueva York: Oxford University Press. 